\title{
Investigation of the effectiveness of ghrelin treatment in lung tissue of rats with sepsis
}

\author{
Yorulmaz $\mathrm{H}^{1}$, Ozkok $\mathrm{E}^{2}$, Ates $\mathrm{G}^{3,4}$, Tamer $\mathrm{S}^{3}$ \\ Aziz Sancar Institute of Experimental Medicine, Istanbul University, Istanbul, Turkey. eozkok@istanbul.edu.tr
}

\begin{abstract}
OBJECTIVE: We aimed to investigate the effects of exogenous ghrelin on cytokine and ghrelin levels, oxidant parameters, and apoptotic genes in lung tissue during sepsis.

BACKGROUND: There was evidence that changes of apoptosis are linked with morbidity and mortality in sepsis. There were scarce studies on the effect of ghrelin on apoptotic genes and endogenous ghrelin levels during sepsis. METHODS: Male Wistar albino rats 200-250 g were separated into four groups; Control, LPS (5 mg/kg), Ghrelin (10 nmol/kg i.v.), and LPS+Ghrelin. Tumor necrosis factor-alpha (TNF- $\alpha$ ), interleukin-10 (IL-10), and ghrelin levels were determined from lung tissue using enzyme-linked immunosorbent assay (ELISA). TNF- $\alpha$, IL-10, $\mathrm{Bcl}-2$, and Bax gene expressions were calculated using quantitative real-time polymerase chain reaction (RTPCR), tissue superoxide dismutase enzyme (SOD) activities and malondialdehyde (MDA) were determined spectrophotometerically.

RESULTS: TNF- $\alpha$ levels decreased in the LPS+Ghrelin group compared with the LPS $(p<0.001)$. IL-10 and MDA levels were found highly significantly increased in the LPS and LPS+Ghrelin groups $(p<0.05)$. Tissue SOD activities were higher in the Ghrelin and LPS+Ghrelin group compared with the LPS $(p<0.05)$. TNF- $\alpha$, and Bax expression levels were increased in the LPS compared with the other groups. IL-10 expression levels were increased in the experimental groups compared with the controls. Bcl-2 expression levels were increased in the Ghrelin and LPS+Ghrelin compared with other groups.

CONCLUSION: Ghrelin treatment attenuated LPS-induced lung injury. Treatment with ghrelin had no impact on serum and tissue ghrelin levels, but it decreased the level of proinflammatory cytokines. We found that ghrelin treatment had an antioxidant effect on SOD levels. Also, ghrelin decreased the activity of proapoptotic Bax and increased antiapoptotic $\mathrm{Bcl}-2$. Our findings suggest that administration of ghrelin may attenuate damage in lung tissue during sepsis (Fig. 4, Ref. 33). Text in PDF www.elis.sk. KEY WORDS: apoptosis, cytokine, ghrelin, lipopolysaccharide.
\end{abstract}

\section{Introduction}

Acute lung injury (ALI) or acute respiratory distress syndrome is commonly caused by sepsis. Acute lung injury, as the most common complication of septic shock, has also attracted more attention from researchers because it may directly affect prognosis of patients with septic shock (1). Elevated production/release of proinflammatory cytokines (e.g. TNF- $\alpha$ and IL-6) and excessive reactive oxygen species (ROS) generation can cause lung injury in sepsis $(2,3)$.

The main sources of ROS in the lung during sepsis are inflammatory cells and mitochondria. Production of ROS leads to

${ }^{1}$ Halic University, Medical Faculty, Istanbul, Turkey, ${ }^{2}$ Istanbul University, Aziz Sancar Institute of Experimental Medicine, Department of Neuroscience, Istanbul, Turkey, ${ }^{3}$ Istanbul University, Istanbul Medical Faculty, Department of Physiology, Istanbul, Turkey, and ${ }^{4}$ Istanbul Yeni Yuzyil University, Medical Faculty, Department of Physiology, Istanbul, Turkey

Address for correspondence: E. Ozkok, MD, Istanbul University, Aziz Sancar Institute of Experimental Medicine, Department of Neuroscience, Vakif Gureba Cad, 34280, Istanbul, Turkey. Phone: $+212.4142000 / 33355$

Acknowlegments: Our study was supported by Scientific Research Projects Coordination Unit of Istanbul University (Project number 42363). lipid, protein, and extracellular matrix damage, which increases pulmonary inflammation (4).

The presence of high serum malondialdehyde (MDA) levels supports the hypothesis that increased oxidative stress, particularly lipid peroxidation, contributes to sepsis pathophysiology (5).

The severity of ALI is associated with the intensity of pulmonary peroxide nitrite, a strong oxidative substance involved in oxidative stress. Peroxide nitrite generation is affected by superoxide dismutase (SOD) (6). Superoxide dismutase (SOD) is a component of antioxidant response and catalyzes the conversion of superoxide anions to hydrogen peroxide (7).

In lungs affected by sepsis, the death of several cell populations, including neutrophils and alveolar macrophages, has been observed. Apoptosis represents an intentional pathway for the removal of these cells, contributing to resolution of the acute pulmonary inflammation (8).

The best-studied mechanisms of apoptosis regulation involve members of the Bcl-2 family (9).

Bcl-2 family members Bcl-2 and Bax play important roles in sepsis-induced pulmonary epithelial cell apoptosis, and cell survival is associated with the ability of cells to maintain a homeostatic level of Bcl-2 (10). 


\section{$585-590$}

Ghrelin exhibits an antiapoptotic effect in several cell types, prevents lipid peroxidation, decreases antioxidant enzyme activity, and protects against sepsis-induced acute respiratory distress syndrome in rats (11).

Exogenous ghrelin was shown to attenuate lung injury and mortality in animals in previous studies (12).

In this study, we aimed to evaluate the effects of ghrelin on pro-inflammatory cytokine TNF- $\alpha$, the anti-inflammatory cytokine IL-10, oxidant parameters SOD and MDA, pro-apoptotic Bax, and anti-apoptotic Bcl-2 genes in lung tissue of septic rats.

\section{Materials and methods}

\section{Experimental groups}

In this study, male adult Wistar albino rats (200-250 g) were divided into four groups, each composed of eight rats: (1) Control group, (2) LPS group, (3) Ghrelin group, and (4) LPS+Ghrelin group. The animals were fed with a commercial diet and tap water ad libitum, housed in cages kept at a controlled temperature (22 $\pm 2{ }^{\circ} \mathrm{C}$ ), humidity (55 to $60 \%$ ), with a 12 -h light/dark cycle. This study was conducted at the University of Istanbul Experimental Research Center, (Resolution No: 2013/123).

\section{Experimental procedures}

The control group was injected with saline. Rats were injected twice with LPS at 12-hour intervals: i.v. and i.p. $(5 \mathrm{mg} / \mathrm{kg}$ in $1 \mathrm{~mL}$ of $0.9 \% \mathrm{NaCl})$ in the LPS and LPS+Ghrelin groups. Ghrelin (10 $\mathrm{nmol} / \mathrm{kg}$ ) was given using an intravenous injection in the ghrelin and LPS+Ghrelin groups. The rats were anesthetized with sodium pentothal (i.p. $30 \mathrm{mg} / \mathrm{kg}$ ). Rats were decapitated 24 hours after first injection. Lung tissues were removed and stored at $-80{ }^{\circ} \mathrm{C}$ until required for analysis.
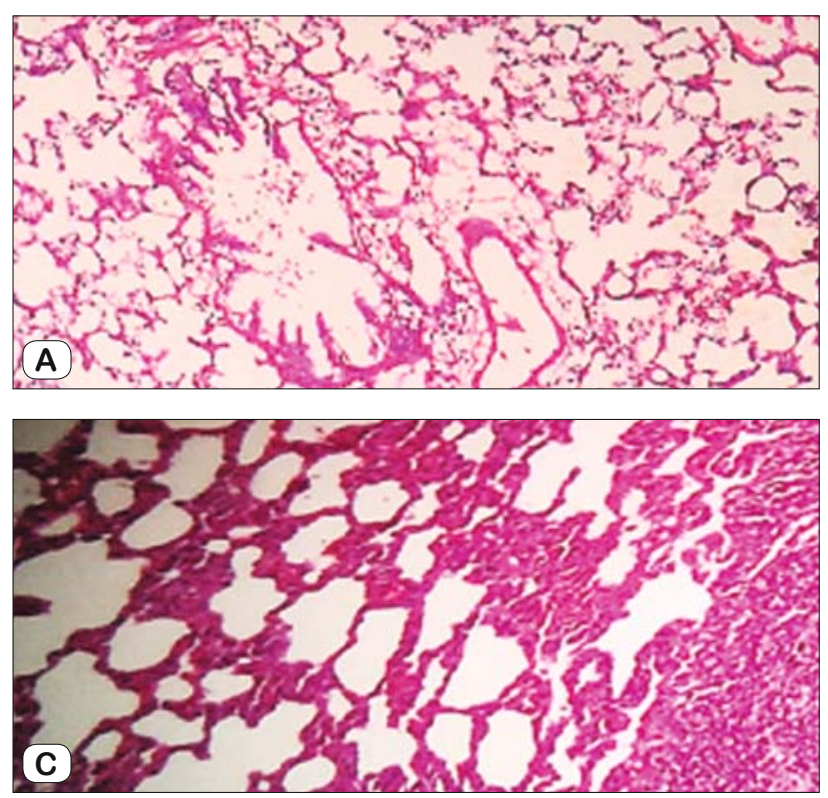

\section{ELISA (enzyme-linked ımmunosorbent assay) procedure}

The levels of total ghrelin (Cat. \# EZRGRT-91K - EMD Millipore Corparation, Billerica), TNF- $\alpha$ (Cat. 865.000.096 Diaclone, France), IL-10 (Cat. 670.070.096 - Diaclone, France), and the activities of SOD (ESOD-100, Bioassay system) were measured using specific ELISA kits for rats in homogenized lung tissue.

\section{Lipid peroxidation procedure}

Lipid peroxide levels in lung tissue were determined by measuring the levels of MDA. In this method, the end products of lipid peroxidation were measured with thiobarbituric acid (TBA- Sigma, Aldrich) in acid and warm conditions spectrophotometrically (Shimadzu, JAPAN) in $532 \mathrm{~nm}$.

\section{Histologic procedure}

The lung tissue samples were fixed in $10 \%$ buffered formalin and embedded in paraffin wax. Five-micrometer-thick sections were placed on polylysine-coated slides and stained with hematoxylin and eosin (H\&E). The slides were evaluated under light microscopy (Olympus BX51; Olympus Corp., Tokyo, Japan) at $40 \times$ magnification.

\section{Gene expression procedure}

After the rats were sacrificed, lung tissue specimens were taken, and the tissues were grounded into powder in liquid nitrogen. Total RNA was extracted using RNAzol RT reagent extraction with reference to the method on the kit. RNA was reverse-transcribed into cDNA. Twenty-four micrograms of RNA were reverse-transcribed to cDNA. The resulting cDNAs were amplified using polymerase chain reaction (PCR) with specific primers for rat Bcl-2 (forward CAAGCCGGGAGA-
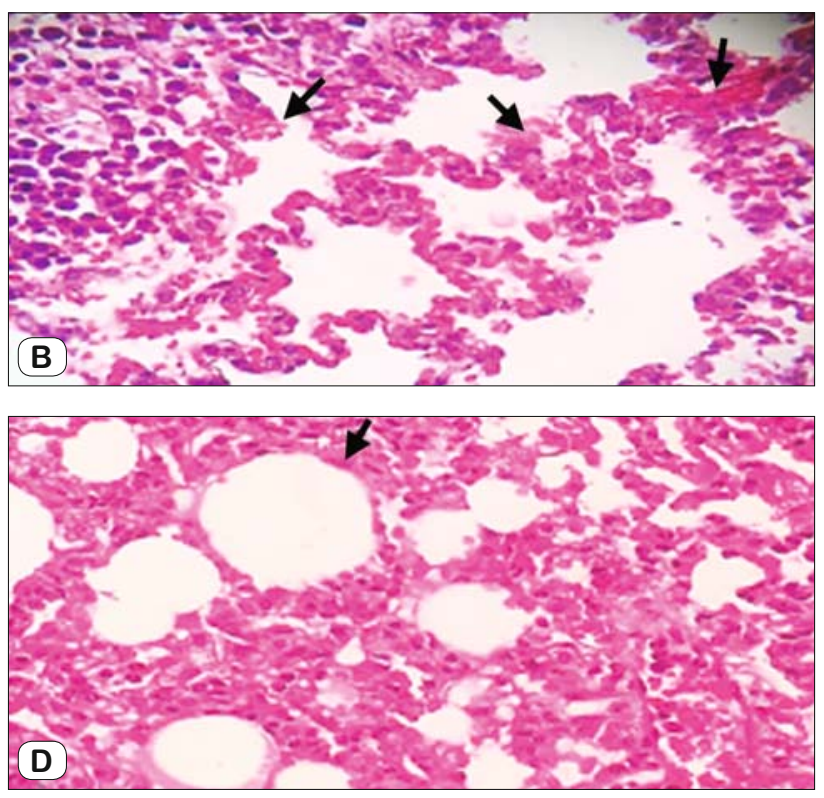

Fig. 1. Section of lung tissue from control group stained with H\&E, $x 40$ magnification (A). Section of lung tissue from LPS group, $x 40$ magnification, Arrows show leukocytes infiltration and alveolar collapse (B). Section of lung tissue from Ghrelin group, $\mathbf{x} 40$ magnification (C). Section of lung tissue from LPS+Ghrelin group, $\mathbf{x} 40$ magnification (D). 

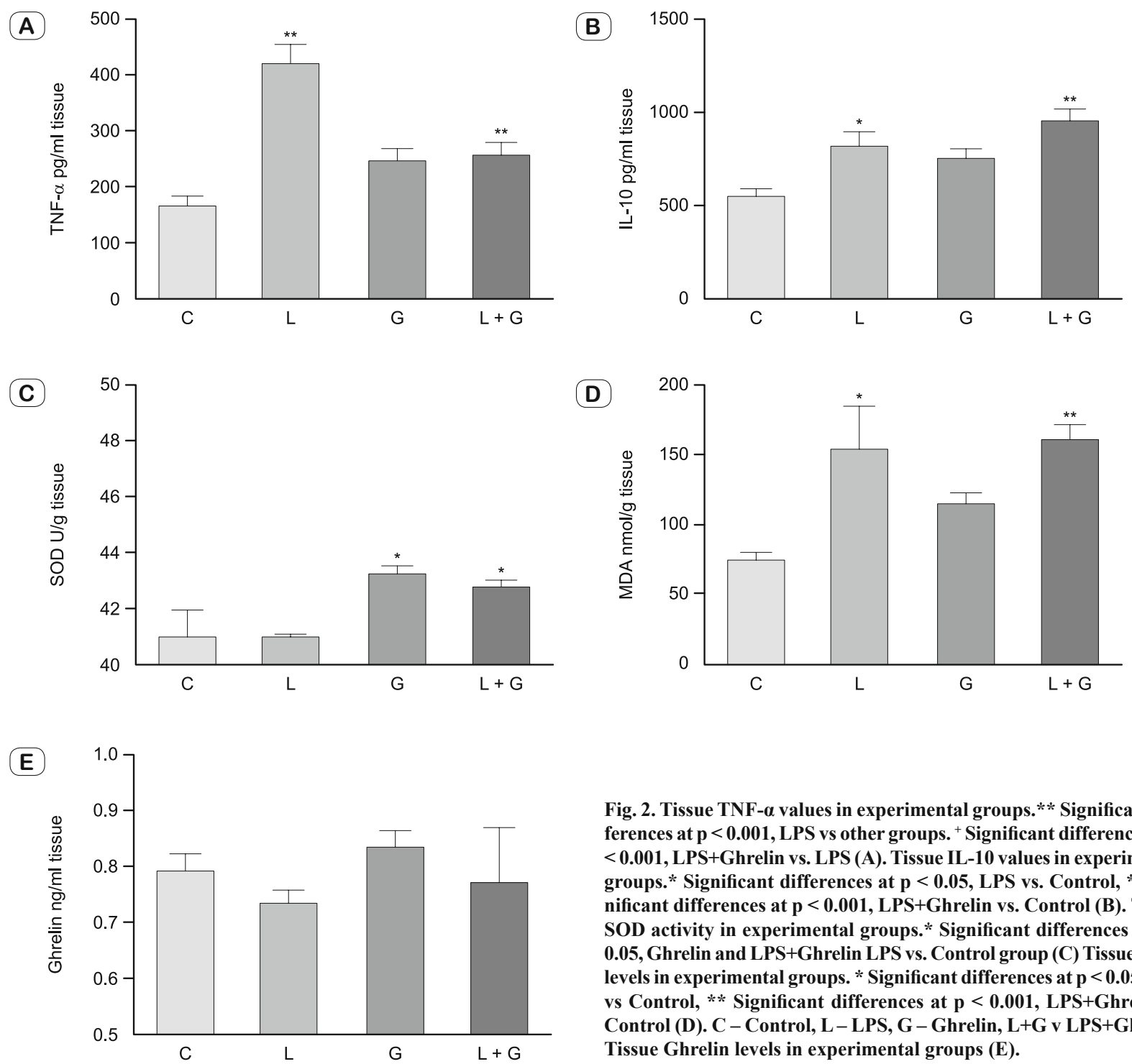

ACAGGGTA; reverse CCCACCGAACTCAAAGAAGGC), rat Bax (forward CCGAGAGGTCTTCTTCCGTGTG; reverse GCCTCAGCCCATCTTCTTCCA), rat TNF- $\alpha$ (forward CACACGAGACGCTGAAGTAG; reverse GAGCAGAGGTTCAGTGATGTAG) and rat IL-10 (forward CTGCAGGACTTTAAGGGTTACT; reverse GAGTGTCACGTAGGCTTCTATG). The upstream primer of housekeeping gene $\beta$-actin was 5 '-AACCCT AAG GCC AAC CGT GAA AAG-3' and its downstream primer was 5'-TCATGAGGTAGTCTGTCAG-3'; the product length was 241 bp. For Bcl-2, Bax, TNF- $\alpha$, and IL-10, the PCR reaction was conducted at 45 cycles for the lungs. Each cycle consisted of 15 seconds at $95{ }^{\circ} \mathrm{C}, 25$ seconds at $54{ }^{\circ} \mathrm{C}$, and 30 seconds at $72{ }^{\circ} \mathrm{C}$. The amount of mRNA for each gene was normalized using $\beta$-actin, and the relative expression levels were calculated using the $2^{-\Delta \Delta \mathrm{Ct}}$ method. Relative mRNA levels of each gene in the control group samples were served as a calibrator, and the

corresponding mRNA levels in the experimental group were expressed as fold changes as compared with that of control samples.

\section{Statistical analyses}

Overall statistical significance between the groups was tested with one-way ANOVA or Kruskal-Wallis test, depending on normality of distribution. In all cases, $\mathrm{p}<0.05$ was set as the limit of significance.

\section{Results}

\section{Histologic results}

Tissue samples from the control and ghrelin rats revealed normal lung histology. Inflammation of the alveolar wall, leukocyte infiltration and aggregation of leukocytes in air spaces or vessel wall, thickness of alveolar wall, and alveolar collapse were ob- 


\section{$585-590$}

served in the LPS group. Ghrelin treatment attenuated the LPSinduced increase in lung injury (Fig. 1).

\section{Cytokine results}

Tissue TNF- $\alpha$ levels were found to be highly significant in the LPS ( $p<0.001)$. In LPS + Ghrelin groups TNF- $\alpha$ levels decreased compared with the LPS group ( $<<0.001)$ (Fig. 2A).

Tissue IL-10 levels were found to be significantly higher in the LPS and LPS+Ghrelin groups than in the control groups $(\mathrm{p}<$ $0.05, \mathrm{p}<0.001$, respectively) (Fig. 2B).

\section{Superoxide dismutase results}

Tissue SOD activities were higher in the Ghrelin and LPS + Ghrelin group compared with the control group $(\mathrm{p}<0.05)$ (Fig. 2C).

Serum SOD activites were increased in the LPS+Ghrelin group compared with other groups $(\mathrm{p}<0.05)$ (Fig. 3A).

\section{Lipid peroxidation results}

MDA values were increased in both the LPS and LPS+Ghrelin groups compared with the Control group $(\mathrm{p}<0.05$, $\mathrm{p}<0.001$, respectively) (Fig. 2D).

\section{Ghrelin results}

There were no significant differences between the groups in tissue and serum ghrelin levels ( $p>0.05$ for both) (Figs 2E and 3B).

\section{Gene expression results}

The mean tissue concentration of Bcl-2 gene expression in LPS+Ghrelin group showed a 11.62-fold increase, the ghrelin group showed a 4.97 fold increase, and the LPS group had a 1.62fold increase with respect to the control rats (Fig. 4A).

The mean tissue concentrations of Bax gene expression in the LPS group showed a 25.14-fold increase, a 4.06-fold increase in LPS+Ghrelin group, and the ghrelin group had a 1.77-fold increase with respect to the control rats (Fig. 4B).

In comparison with the controls, the mean tissue concentrations of TNF- $\alpha$ gene expression in the LPS group showed a 26.42-fold increase, the ghrelin group had a 1.07-fold increase, and LPS + Ghrelin group showed a 3.96-fold increase (Fig 4C).

The mean tissue concentrations of IL-10 gene expression in LPS+Ghrelin group showed a 7.8-fold increase, a 4.66-fold increase in the ghrelin group, and there was a 4.5 -fold increase in the LPS group, with respect to control rats (Fig. 4D).

\section{Discussion}

LPS could progress to septicemia and further lead to systemic inflammatory response syndrome, and even the most common and acute lung injury. The physiologic characteristics of the lung make it the first target organ to be involved and attacked (13). The lung is frequently the first organ to fail during the sequential development of multiple organ dysfunction in sepsis. Severe sepsis, when accompanied by acute respiratory distress syndrome, continues to be the leading cause of death in intensive care units, with a mor-
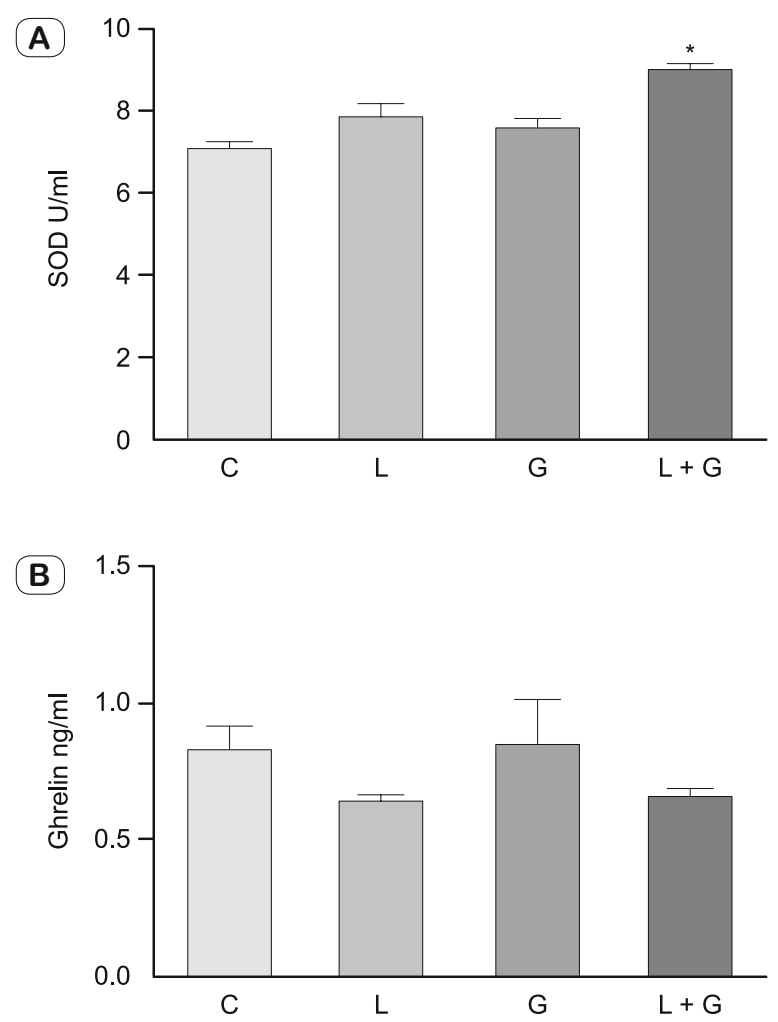

Fig. 3. Serum SOD activitiy in experimental groups. * Significant differences at $p<0.05$. LPS + Ghrelin group versus other groups (A). Serum Ghrelin levels in experimental groups (B).

tality that has remained over $40 \%$ (14). The early phase of sepsis is dominated by a hyperinflammatory state mediated by systemic production of inflammatory cytokines, including interleukin 1 (IL$1)$ IL-6, and TNF- $\alpha$. This hyperinflammatory "cytokine storm" may lead to significant end-organ damage and death in a subset of patients. TNF- $\alpha$, as a pro-inflammatory factor, is the first multifunctional cytokine produced from LPS-stimulated monocytes and macrophages, which elicits the inflammatory cascade and contributes to the severity of lung injury (15). In our study, tissue TNF- $\alpha$ levels were found to be highly significant in the LPS group. Also the mean tissue concentrations of TNF- $\alpha$ gene expression in LPS group showed a 26.42-fold increase compared with the controls.

Ghrelin has been reported to downregulate cytokines in human endothelial cells (16). In this regard, studies have demonstrated that treatment with ghrelin in a rat model of endotoxemia significantly decreased circulating levels of cytokines (17). In this study, concentrations of TNF- $\alpha$ gene expression in LPS + Ghrelin groups decreased compared with the LPS group. The mean tissue concentrations of TNF- $\alpha$ gene expression in the LPS+Ghrelin group were increased 3.96-fold with respect to the control rats.

Concomitant with the initial hyperinflammatory response is a near-simultaneous production of anti-inflammatory cytokines, including IL-10, that serves to balance the inflammatory state (18). In this study, tissue IL-10 levels and gene expression were shown to increase in the LPS group in a reaction to the inflammatory response. IL-10, a potent anti-inflammatory cytokine, has 

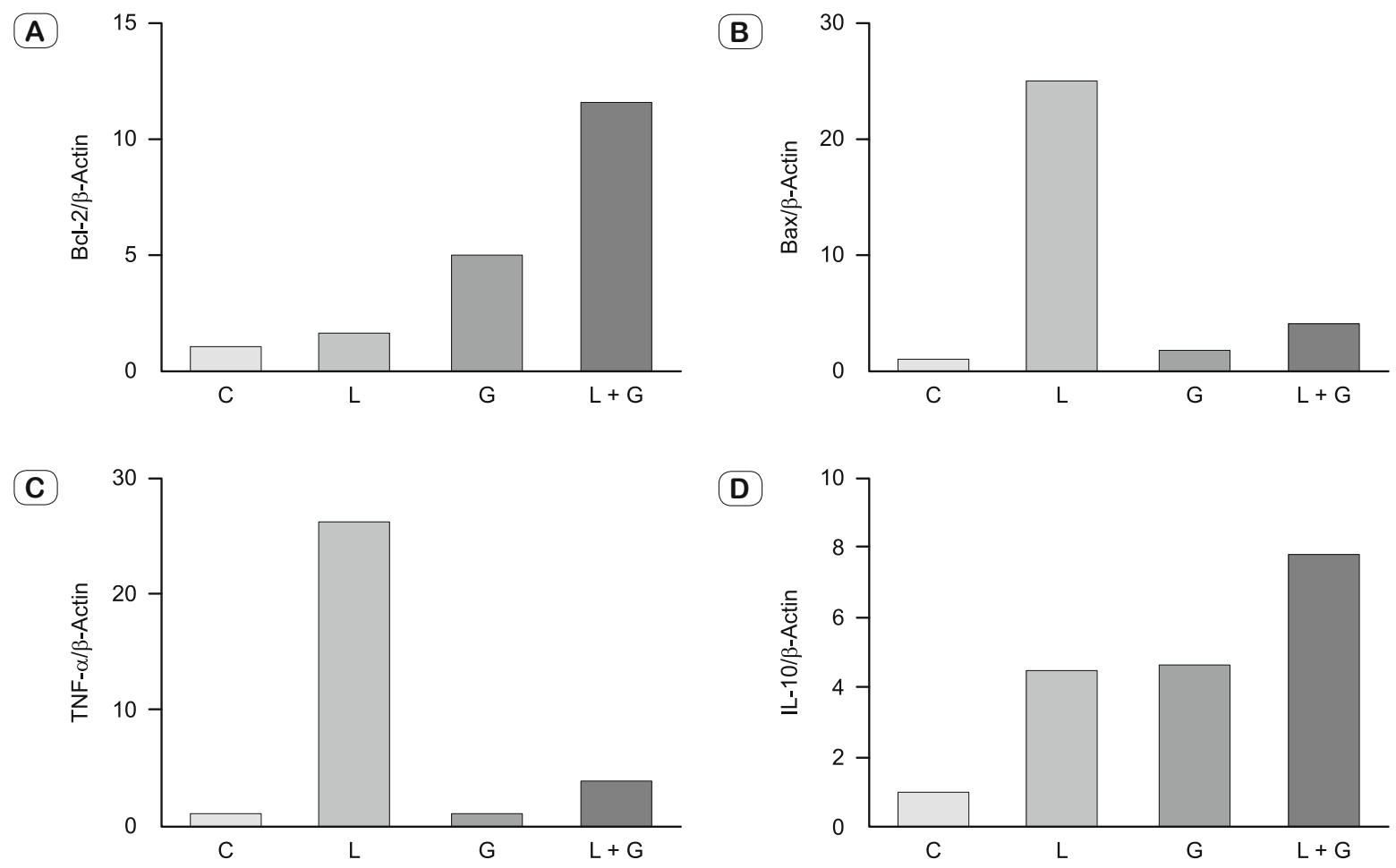

Fig. 4. Bcl-2, Bax, TNF- $\alpha$, IL-10 gene expresssions results (A-D).

been shown to predict poor prognosis in patients with sepsis, and modulation of IL-10 in selected animal models of sepsis improved survival (19). While the IL-10 gene expression in the LPS group showed a 4.5-fold increase, in the LPS+Ghrelin group IL-10 gene expression showed a 7.8-fold increment.

Sepsis and endotoxaemia lead to the production of ROS, which has been assumed to play a role in the induction of many proinflammatory cytokines and mediators important in producing the acute inflammatory responses associated with sepsis (6).

MDA levels are commonly considered as markers of oxidative stress, and antioxidant status is increased in patients with acute respiratory distress syndrome (20). In our study, MDA values were increased in the LPS group compared with the control animals.

SOD is the only antioxidant enzyme that can scavenge superoxide, and it has been reported to be markedly decreased in sepsisinduced ALI (21). The present study revealed that the antioxidant capacity was significantly decreased during sepsis. Previous studies demonstrated that the level of extracellular SOD activity negatively correlated with the severity of lung injury (22).

Ghrelin improved SOD activity (23). Tissue SOD activities were higher in the Ghrelin and LPS+Ghrelin group. Serum SOD activities were higher in the LPS+Ghrelin group. Survival studies have provided the most compelling evidence that apoptotic changes in tissues can contribute to morbidity and mortality that is directly associated with sepsis (24). The most studied mechanism is apoptotic regulation by two families of downstream mediators, the anti-apoptotic Bcl-2 family and the pro-apoptotic Bax family (25). LPS augmented expression of the pro-apoptotic protein Bax
(26). In our study, Bax expression levels were increased in the LPS groups compared with the other groups. The Bcl-2 protein is antiapoptotic and is located within the mitochondria, endoplasmic reticulum, and nuclear membranes, where most ROS are generated to exert their apoptotic effects. Whereas Bcl-2 prevents the release of Cyt $\mathrm{c}$ into the cytosol after exposure to cytotoxic stimuli, proapoptotic Bax induces the mitochondrial release of Cyt c, which activates the caspase cascade and apoptosis (27). We showed that Bcl-2 expression levels were significantly increased in the ghrelin and LPS + Ghrelin groups compared with the other groups.

The lungs are one of the earliest organs to be damaged in the course of sepsis and therefore, the extent of lung injury is an important clue to determine the extent of inflammation (28). Liu et al. observed pulmonary edema caused by the increase of capillary permeability using electron microscopy, and structural damage of type II alveolar epithelial cells in H\&E staining of lung tissue sections during sepsis (29). In parallel, we demonstrated lung injury in sections from rats with LPS treatment. However, ghrelin treatment attenuated the LPS-induced increase in lung injury. Rat ghrelin is beneficial in rat models of polymicrobial sepsis (30). Luo et al. showed that systemic inflammation was negatively correlated with plasma ghrelin in chronic obstructive pulmonary disease (31). Recent studies have shown that ghrelin can attenuate severe sepsis-induced ALI and mortality through the inhibition of NF- $\kappa B$ (32). Serum ghrelin levels have been reported to be decreased or increased after LPS injection depending on the timing of disease course. In the literature, the serum ghrelin levels increased at 16 hours after exposure to $\operatorname{LPS}(17,33)$. 


\section{$585-590$}

We administered exogenous ghrelin through intravenous injection. There were no significant differences among the ghrelin groups in tissue and serum ghrelin levels. Although there was no statistically significant difference, ghrelin levels were decreased in LPS group, and increased in the LPS + Ghrelin group. However, exogenous ghrelin treatment showed a positive effect on IL-10, $\mathrm{SOD}, \mathrm{Bax}$ and Bcl-2 gene levels during sepsis. In conclusion, we propose that administration of ghrelin may attenuate lung tissue damage during sepsis.

\section{References}

1. Ware LB, Matthay MA. The acute respiratory distress syndrome. N Engl J Med 2000; 342: 1334-1349.

2. Bánfi A, Tiszlavicz L, Székely E et al. Development of bronchus-associated lymphoid tissue hyperplasia following lipopolysaccharide-induced lung inflammation in rats. Exp Lung Res 2009; 35 (3): 186-197.

3. Powell CS, Jackson RM. Mitochondrial complex I, aconitase, and succinate dehydrogenase during hypoxia-reoxygenation: modulation of enzyme activities by MnSOD. Am J Physiol Lung Cell Mol Physiol 2003; 285: 189-198.

4. Dahl M, Bauer AK, Arredouani M et al. Protection against inhaled oxidants through scavenging of oxidized lipids by macrophage receptors MARCO and SR-AI/II. J Clin Invest 2007; 117: 757-764.

5. Moustafa AH, Ali EM, Mohamed TM, Abdou HI. Oxidative stress and thyroid hormones in patients with liver diseases. Eur J Intern Med 2009; 20: 703-708.

6. Chabot F, JA Mitchell, JM Gutteridge, TW Evans. Reactive oxygen species in acute lung injury. European Respiratory Journal 1998; 11(3): 745-57.

7. Kinnula VL, Crapo JD. Superoxide dismutases in the lung and human lung diseases. Am J Respir Crit Care Med 2003; 167: 1600-1619.

8. Cox G, Crossley J, Xing Z. Macrophage engulfment of apoptotic neutrophils contributes in resolution of acute pulmonary inflammation in vivo. Am J Respir Cell Mol Biol 1995; 12: 232-237.

9. Youle RJ and Strasser A. The BCL-2 protein family: opposing activities that mediate cell death. Nat Rev Mol Cell Biol 2008; 9: 47-59.

10. Hotchkiss R, Swanson PE, Knudson CM et al. Overexpression of $\mathrm{Bcl}-2$ in transgenic mice decreases apoptosis and improves survival in sepsis. J Immunol 1999; 162: 4148-4156.

11. Li B, Zeng M, He W et al. Ghrelin protects alveolar macrophages against lipopolysaccharide-induced apoptosis through growth hormone secretagogue receptor 1a-dependent c-Jun N-terminal kinase and Wnt/ 3 catenin signaling and suppresses lung inflammation. Endocrinology 2015; 156 (1): 203-217.

12. Zhou X, C Xue. Ghrelin attenuates acute pancreatitis inducelung injury and inhibits substance P expression. American Journal of the Medical Sciences 2010; 339 (1): 49-54.

13. Bastarache JA, Ware LB, Bernard GR. The role of the coagulation cascade in the continuum of sepsis and acute lung injury and acute respiratory distress syndrome. Semin Respir Crit Care Med 2006; 27: 365-376.

14. Rubenfeld GD, Caldwell E, Peabody E, Weaver J, Martin DP, Neff $M$ et al. Incidence and outcomes of acute lung injury. N Engl J Med 2005; 353: 1685-1693.
15. Giebelen IA, van Westerloo DJ, LaRosa GJ, et al. Local stimulation of a 7 cholinergic receptors inhibits LPS-induced TNF-a release in the mouse lung. Shock 2007; 28: 700.

16. Li WG, Gavrila D, Liu X, et al. Ghrelin inhibits proinflammatory responses and nuclear factor-kappaB activation in human endothelial cells. Circulation 2004; 109 (18): 2221-2226.

17. Chang L, Zhao J, Yang J, Zhang Z, Du J, Tang C. Therapeutic effects of ghrelin on endotoxic shock in rats. Eur J Pharmacol 2003; 473 (2-3): 171-176.

18. Rittirsch D, Flierl MA, Ward PA. Harmful molecular mechanisms in sepsis. Nat. Rev. Immunol 2008; 8: 776-787.

19. Kahlke VC, Dohm T, Mees K, Bro“tzmann, S, Schreiber, Schro"der J. Early interleukin-10 treatment improves survival and enhances immune function only in males after hemorrhage and subsequent sepsis. Shock 2002; 18: 24-28.

20. Macdonald J, Galley HF, Webster NR. Oxidative stress and gene expression in sepsis. Br J Anaesth 2003; 90: 221-232.

21. Suntres ZE, Shek PN. Prophylaxis against lipopolysaccharideinduced acute lung injury by a-tocopherol liposomes. Crit Care Med 1998; $26: 723$.

22. Yen CC, YW Lai, HL Chen et al. Aerosolized human extracellular superoxide dismutase prevents hyperoxia-induced lung injury. PLoS One 2011; 6 (10): e26870.

23. Zeng M, He W, Li L et al. Ghrelin attenuates sepsis-associated acute lung injury oxidative stress in rats. Inflammation 2015; 38 (2): 683-690.

24. Ayala A, Lomas JL, Grutkoski PS, Chung CS. Pathological aspects of apoptosis in severe sepsis and shock? Int J Biochem Cell Biol 2003; 35: 7-15.

25. Adams JM, S Cory. The Bcl-2 protein family: arbiters of cell survival. Science 1998; 281: 1322.

26. Karahashi H, Michelsen KS, Arditi M. Lipopolysaccharide-induced apoptosis in transformed bovine brain endothelial cells and human dermal microvessel endothelial cells: the role of JNK. J Immunol 2009; 1; 182 (11): 7280-7286.

27. Tan C, Dlugosz PJ, Peng J et al. Auto-activation of the apoptosis protein Bax increases mitochondrial membrane permeability and is inhibited by Bcl-2. J Biol Chem 2006; 281: 14764-14775.

28. Riedemann NC, Guo RF, Ward PA. The enigma of sepsis. J Clin Invest 2003; 112: 460-467.

29. Liu W, Shan LP, Dong XS, Liu XW, Ma T, Liu Z. Effect of early fluid resuscitation on the lung in a rat model of lipopolysaccharide-induced septic shock. Eur Rev Med Pharmacol Sci 2013; 17 (2): 161-169.

30. Wu R, Dong W, Zhou M et al. Ghrelin improves tissue perfusion in severe sepsis via downregulation of endothelin-1. Cardiovasc Res 2005; 68: 318-326.

31. Luo FM, Liu XJ, Li SQ et al. Circulating ghrelin in patients with chronic obstructive pulmonary disease. Nutrition 2005; 21 (7-8): 793-798.

32. Wu R, Dong W, Cui $X$ et al. Ghrelin down-regulates proinflammatory cytokines in sepsis through activation of the vagus nerve. Ann Surg 2007; 245: 480-486.

33. Hataya Y, Akamizu T, Hosoda $\mathbf{H}$ et al. Alterations of plasma ghrelin levels in rats with lipopolysaccharide-induced wasting syndrome and effects of ghrelin treatment on the syndrome. Endocrinology 2003; 144 : $5365-5371$.

Received May 10, 2017. Accepted June 3, 2017. 